\title{
Encuadres periodísticos y reforma energética: Contribución eficaz a la imagen política de Enrique Peña Nieto
}

\author{
Journalistic Frameworks and Energy Reform: Effective Contribution to the \\ Political Image of Enrique Peña Nieto
}

\author{
Reyna Madai BAÑUELOS RAMÍREZ \\ Benemérita Universidad Autónoma de Puebla \\ reyna.bañuelos@correo.buap.mx
}

\begin{abstract}
Resumen
La teoría del frame, framing, encuadre o marco se entiende como el tratamiento que realizan los medios de comunicación en la reconstrucción de los hechos para darle un enfoque particular a la noticia, donde ciertos aspectos son dados a conocer y otros son minimizados. Esta perspectiva se aplica para analizar la manera como los medios de comunicación encuadraron y guiaron el debate público para apoyar la aprobación de la reforma energética del presidente mexicano Enrique Peña Nieto. Mediante la participación decidida de las dos principales cadenas de televisión nacional, señalaron a los distintos públicos cómo concebir y entender el significado y repercusiones de esta reforma estructural. En ese sentido, los medios jugaron un papel sustantivo en la construcción de la percepción social y la aceptación de ese cambio fundamental en la legislación del país. Los noticiarios estelares fueron una vía importante para informar y socializar el tema de la reforma $y$, sobre todo, para posicionar la imagen del Presidente.
\end{abstract}

\begin{abstract}
The theory of frame or framing is understood as the media treatment in the reconstruction of events and to give a particular focus in the news, where certain aspects are disclosed, and others are minimized. This perspective is applied to analyze the way in which the media framed and guided the public debate to support the approval of the energy reform by Mexican President Enrique Peña Nieto. Through the determined participation of the two main national 
television networks, they pointed out to the different publics how to conceive and understand the meaning and repercussions of this structural reform. In this sense, the media played a substantial role in the construction of social perception and acceptance of this fundamental change in the country's legislation. Stellar newscasts were an important way to inform and socialize the issue of reform and, above all, to position the image of the President.

Palabras clave: Reforma energética, encuadres periodísticos y discurso político Key Words: Energy Law, Framing News and Political Speeches.

\section{Introducción}

La aprobación de la reforma energética fue señalada por el propio gobierno como "el gran logro" de la administración pues, desde la expropiación petrolera en 1938 y la nacionalización de la industria eléctrica en 1960, no se realizaban cambios estructurales a la Constitución que implicaran una reorientación política de esa magnitud. En ese sentido, asumieron que las reformas estructurales podrían considerarse como el principal distintivo de su gestión para transformar el país. Con esta reforma se realizaron cambios a los artículos: $25^{\circ}, 27^{\circ}$ y $28^{\circ}$, además de otras leyes secundarias, modificando estatutos sobre dos de las empresas más emblemáticas del país, como son Petróleos Mexicanos (PEMEX) y Comisión Federal de Electricidad (CFE). La iniciativa sobresalió en la agenda de gobierno y fue ejecutada durante el primer año de gestión de EPN ${ }^{1}$.

Como antecedente de esta reforma es de mencionar que en los 266 compromisos que realizó durante su campaña rumbo a la presidencia, EPN se comprometió a disminuir las tarifas eléctricas en beneficio de la población y la industria del país. Ya como presidente electo, destacó la importancia de las reformas estructurales para lograr el crecimiento económico de México, en especial la reforma energética para multiplicar la capacidad de exportación de hidrocarburos, contemplando la participación de grupos privados (nacionales y extranjeros) sin que el Estado perdiera la rectoría sobre el sector. Señaló que para avanzar

\footnotetext{
${ }^{1}$ En el texto se utilizarán las siglas EPN para hacer referencia a Enrique Peña Nieto.
} 
se tenía que romper viejos paradigmas y reconocer que para desarrollar mayor infraestructura era necesaria la participación de la iniciativa privada (Forbes, 2012).

En el discurso de la toma de posesión EPN mencionó que uno de los ejes de su gobierno sería un México próspero y que lograría el consenso necesario para impulsar las reformas energética, hacendaria y sobre el régimen de seguridad social. (Mensaje a la Nación, 2012). Para ello, consensó el "Pacto por México", un acuerdo firmado por las diversas fuerzas políticas (PRI, PAN y PRD) para asegurar la autorización de un paquete de reformas legislativas durante su sexenio. En este pacto se establecieron cinco acuerdos, uno de ellos hace referencia a "fomentar el crecimiento económico, el empleo y la competitividad", además de impulsar una reforma energética que "convierta a ese sector en uno de los más poderosos motores del crecimiento económico a través de la atracción de inversión, el desarrollo tecnológico y la formación de cadenas de valor" (Pacto por México, 2012). Posteriormente, dentro del Plan Nacional de Desarrollo (PND 2013-2018), se hizo referencia al ámbito económico y contempló la estabilidad macroeconómica del país, el empleo de calidad, el acceso a servicios de telecomunicaciones, el abastecimiento de energía al país con precios competitivos e infraestructura, entre otros.

En este contexto, el Presidente presentó el 12 de agosto de 2013 la iniciativa de reforma energética a la Cámara de Senadores para su debate. Sin embargo, los partidos políticos comprometidos con el Pacto por México manifestaron su desacuerdo con la iniciativa. El PRD, junto con otros partidos de izquierda, fueron los principales opositores al considerar que los cambios propuestos por EPN pretendían la privatización de PEMEX. Señalaron que, si bien era importante modernizar al sector, no era conveniente hacer cambios determinantes al espíritu de la ley. Ante ello, el PRD propuso una consulta ciudadana para que la iniciativa fuera puesta a discusión por parte de la población, cosa que no alcanzó el consenso necesario. En esa condición, el 12 de diciembre se concluyó el proceso de discusión y la iniciativa se aprobó por ambas cámaras. El 20 de diciembre de 2013 fue promulgada en el Diario Oficial de la Federación.

Facultad de Ciencias Políticas, Sociales y de la Comunicación Universidad de La Laguna 
En la iniciativa de reforma energética propuesta por EPN, se señalaron como ejes principales:

- El fortalecimiento del papel del Estado como rector de la industria petrolera

- Crecimiento económico para aprovechar los recursos energéticos en favor de mayor inversión y generación de más empleos, promover el abasto de energía y a costos competitivos

- Desarrollo incluyente, democratizar la productividad y la calidad de vida de la población en las distintas regiones del país

- Seguridad energética, la procuración continua, diversificada y económica del suministro energético para ésta y las siguientes generaciones

- Transparencia, acceso a la información sobre la administración del patrimonio energético nacional

- Sustentabilidad y protección del medio ambiente" (Iniciativa de Reforma, 2013).

Además, se propusieron cambios al artículo 27 constitucional para quitar la "restricción incorporada en 1960 que impide al Estado la utilización de contratos en sus actividades de explotación de hidrocarburos" (Iniciativa de Reforma, 2013). Sin embargo, en los comunicados de prensa y los spots publicitarios la iniciativa se resumió en cinco puntos:

- Fortalecer a CFE y PEMEX

- Retomar el texto de Lázaro Cárdenas palabra por palabra sobre el artículo $27^{\circ}$ constitucional

- PEMEX y CFE no se venden ni se privatizan

- Mejores tarifas de luz y gas

- Mayor número de empleos.

Adicionales a ello, son de destacar las distintas posiciones de los medios de comunicación sobre la reforma, a través de variados tratamientos, enfoques y coberturas para mantener el tema en la agenda pública. Aunque existieron posiciones diversas, los principales periódicos y medios audiovisuales referentes apoyaron al gobierno en su propósito de conseguir que los 
ciudadanos pensaran positivamente sobre la reforma. Mediante la participación decidida de las dos principales cadenas de televisión nacional de ese momento, dijeron a los distintos públicos cómo concebir y entender el significado y repercusiones de esta reforma estructural (Corona, 2012, Villamil, 2012 y Cantú, 2013). En ese sentido, jugaron un papel sustantivo en la construcción de la percepción social y la aceptación de ese cambio fundamental en la legislación del país. Los noticiarios estelares fueron una vía importante para informar y socializar el tema de la reforma y, sobre todo, para posicionar la imagen del Presidente ${ }^{2}$.

\section{Perspectiva teórica}

La teoría del frame, framing, encuadre o marco ${ }^{3}$ se entiende como el tratamiento que realizan los medios de comunicación en la reconstrucción de los hechos para darle un enfoque particular a la noticia, donde ciertos aspectos son dados a conocer y otros son minimizados. Para ilustrar cómo el frame está implícito en la estructura de un mensaje, Kahneman y Trevesky (2000) explican cómo las variaciones en la descripción de un problema cambian la elección de las personas. A esto lo llaman framing effect, considerado como una etiqueta con dos significados diferentes, la estructura en el mensaje influye para inclinarse por una u otra alternativa. lyengar (1991:21), quien realizó estudios sobre la influencia que tienen en la

\footnotetext{
${ }^{2}$ Un mes antes de la presentación de la iniciativa el CESOP (2013) señaló que un 67\% había escuchado los planes de una iniciativa, el $60 \%$ consideraba PEMEX como más del gobierno que de los mexicanos. El 55\% señalaron necesaria la iniciativa, pero un 54\% decían estar en desacuerdo con la participación de capital privado en este sector. Paramearía (2013a) señaló que para un 57\%, la participación del sector privado significaba privatizar, también señaló que quienes se beneficiarían de una reforma sería en su mayoría empresarios -71\%- y el gobierno -63\%-. En el mes de septiembre Buendía y Laredo (2013) señalaron que los encuestados consideraron la iniciativa de reforma energética la segunda más importante para el país, además que el $61 \%$ dijo la información que conocía hasta el momento la obtuvo de las noticias, $12 \%$ de comerciales y $9 \%$ de redes sociales. En el mes de diciembre posterior a la promulgación Parametría (2013b) señaló el $60 \%$ dijo que con la reforma aumentarían los precios de la luz, gas y gasolina. Concluye que la estrategia de comunicación política que ha llevado a cabo el gobierno federal para informar sobre los cambios en materia energética y sus posibles beneficios, no se traslada a la percepción del beneficios personales" (Parametría, 2013b).
}

${ }^{3}$ Dependiendo del autor y su traducción en los textos lo llaman de una u otra manera.

Facultad de Ciencias Políticas, Sociales y de la Comunicación

Universidad de La Laguna

Avenida César Manrique, s/n; Campus de Guajara

38071 La Laguna, Tenerife (Islas Canarias - España) 
opinión publica el framing en las noticias, define por su parte que el marco lo constituyen "las sutiles alteraciones en la formulación y presentación de los problemas que se juzgan o seleccionan y el término "efecto de los marcos" se refiere a los cambios de decisiones resultantes de tales alteraciones".

Llevado el frame al trabajo periodístico, se entiende que el periodista realiza una abstracción de la realidad y transmite las imágenes que recrea desde su mente a la de las audiencia. A través de los medios de comunicación da un punto de vista sobre la realidad y el acontecer de los hechos. Sádaba (2007:49) señala que los encuadres "en principio surgen como resultado del trabajo periodístico, son parte de todo acercamiento interpretativo a la realidad y de una serie de circunstancias profesionales que acrecientan en el periodista un modo de ver la realidad". Esto la ha llevado a cuestionar la objetividad de la noticia, al sugerir que el framing no sólo es reconstruir los hechos con una parte del universo, Por ello, Wolfsfeld (2011:76) ha dicho que "elegir un frame periodístico es también elegir contar sólo una parte de la historia". En el intercambio de poder por la información, los frames también pueden provenir desde los políticos a través del discurso. "No siempre son los medios de comunicación los encargados de definir asuntos públicos. Los frames definen la realidad pública y los políticos intentan poner en marcha mecanismos estratégicos para definir los asuntos a su conveniencia. (Sádaba, Rodríguez y Bartolomé, 2012). En esta lucha por el poder, algunos autores4 señalan que los presidentes deben saber dominar el arte de la manipulación de los medios de comunicación, con el fin de promover los programas y las causas que creen y, al mismo tiempo, evitar el manipuleo de los propios medios de comunicación (Grabe y Bucy, 2009). En este sentido, Entman (2004) refiere que hay dos maneras de entender la comunicación política (relación entre gobierno y medios de comunicación). Por un lado, están los teóricos hegemónicos quienes creen que los

\footnotetext{
${ }^{4}$ Entendiendo como poder a "la capacidad relacional que permite a un actor social influir de forma asimétrica en las decisiones de otros actores sociales de modo que favorezcan la voluntad, los intereses y los valores del actor que tiene el poder." (Castells, 2012:33).
} 
funcionarios de gobierno mantienen la información dentro de los límites ideológicos. Aunque los líderes entren en conflicto, los acuerdos de élite mantienen una armonía que impide un flujo de información. Por otro, están los teóricos de la indización, que señalan a los medios de comunicación como un vehículo de los funcionarios para criticarse entre sí, reflejan el debate entre los desacuerdos para afectar las políticas a discusión.

Teniendo como referencia lo anterior, se considera que para la presente investigación es de utilidad el modelo de Entman, conocido como "activación de cascada", para identificar como los medios de comunicación se supeditaron a la agenda del gobierno para dar relevancia a la reforma energética, pero no lograron posicionar socialmente lo cambios constitucionales, ni los beneficios que ella traería. Este modelo enfatiza las habilidades de algunos actores para promover o difundir un frame, en el que a manera de metáfora la cascada tiene 5 niveles en la que se desplazan- Parten de la administración (representada por el Presidente y su gabinete), luego está la elite política (Congresistas, cabilderos, académicos y lides de opinión), le siguen los medios de comunicación (periodistas, reporteros, columnista y editores que trabajan para los órganos nacionales importantes), en el cuarto peldaño se ubican los news frames, es decir, la composición entre imágenes y mensajes formados del intercambio de información oficial y extraoficial, entre la elite política y los periodistas de alto nivel. En el último nivel coloca la opinión pública.

El framing se define como "la selección y resalte de algunos aspectos de los acontecimientos 0 issues, que hacen conexiones entre ellos a fin de promover una interpretación particular, evaluación y / o solución" (Entman, 2004:5). En la noticia se da seguimiento a diferentes objetivos que pueden ser eventos políticos, issues y actores (líderes, grupos o naciones). "Ella tiene la función de definir efectos o condiciones de una problemática, identificar la causa, evaluación moral y recomendación de un tratamiento o mejoras" (Entman, 2004:24). La función de definir un problema y recomendar un tratamiento, promueve el apoyo o la oposición a una política pública. Por ello, Entman (2004:06) señala que lo que hace que el frame se distinga del resto de las noticias es la capacidad de estimular una posición. Al 
mismo tiempo, la magnitud de resonancia de un frame está condicionado por la identificación cultural. Tiene mayor potencial para influir cuando se utilizan palabras o imágenes muy destacadas en la cultura. En ese sentido, "son más noticiables, compresibles, memorables y con mayor carga emocional".

Cuadro No. 1

Funciones y objetivos del frame en la noticia

\begin{tabular}{|l|l|l|l|}
\hline \multirow{2}{*}{ Función del Frame } & \multicolumn{3}{|c|}{ Enfoque del Frame } \\
\cline { 2 - 4 } & Issues & Evento & $\begin{array}{c}\text { Actores politicos } \\
\text { (Individuo, Grupo, Nación) }\end{array}$ \\
\hline $\begin{array}{l}\text { Definición del } \\
\text { problema } \\
\text { efectos/condiciones }\end{array}$ & & & \\
\hline $\begin{array}{l}\text { Identificar } \\
\text { causa/agente }\end{array}$ & & & \\
\hline $\begin{array}{l}\text { Recomendación } \\
\text { tratamiento }\end{array}$ & & & \\
\hline Evaluación moral & & & \\
\hline Fuente: Obtenido de Entman (2004:24) "Functions and Objects of News Frames" \\
\hline
\end{tabular}

\section{Metodología de la investigación}

Para identificar el framing de la reforma energética de EPN, se dio seguimiento a los dos noticiarios nocturnos estelares del momento ("El Noticiero" de Televisa y "Hechos Noche" de TV Azteca), durante tres semanas en las que se contabilizaron aquellas notas que hicieran mención a la reforma energética. En promedio cada programa sin cortes comerciales tuvo una duración de 38 minutos. ("El Noticiero" 38 min 45 segundo y "Hechos Noche, 38 min 18 segundo). De todas las notas "El Noticiero" sumó en total 1 hora 47 minutos y "Hechos Noche" 1 hora 32 minutos. En ambos casos fue proporcional el tiempo que los dos noticiarios ofrecieron sobre su trasmisión y el que dedicaron al tema de la reforma, lo que nos permite compararlos por igual.

Facultad de Ciencias Políticas, Sociales y de la Comunicación Universidad de La Laguna Avenida César Manrique, s/n; Campus de Guajara 38071 La Laguna, Tenerife (Islas Canarias - España) 
Figura No. 1

\section{Semanas de análisis}

\begin{tabular}{|c|c|c|c|}
\hline $\begin{array}{l}\text { PRESENTACIÓN DE LA } \\
\text { INICIATIVA }\end{array}$ & & $\begin{array}{c}\text { PROMULGACIÓN DE LA } \\
\text { REFORMA }\end{array}$ & \\
\hline \multirow[t]{2}{*}{12 AL 16 AGOSTO } & 9 AL 13 DICIEMBRE & 16 AL 20 DICIEMBRE & 2013 \\
\hline & $\begin{array}{l}\text { BATE Y APROBACIÓN } \\
\text { ENADO Y CÁMARA DE } \\
\text { DIPUTADOS }\end{array}$ & & \\
\hline
\end{tabular}

Fuente: Elaboración propia con información del análisis

Las notas encontradas fueron separadas por temáticas, identificadas de manera deductiva y, en cada una, se identificó el enfoque (positivo, negativo y neutro) y los actores políticos, considerando aquellos que tuvieron un espacio significativo, dieron alguna declaración en apoyo al discurso presidencial o bien lo cuestionaron. Estos fragmentos en la noticia se consideran dentro de la investigación como sound bite ${ }^{5}$. Para identificar el framing se realizó un análisis cualitativo sobre 4 de 7 temáticas encontradas a partir del modelo de Entman (2004). De cada nota se identificó primero el objetivo (issue, evento o personaje), posteriormente los cuatro elementos que debe contener el framing: definición del problema, causa, evaluación moral y recomendación del tratamiento. Para determinar el framing se seleccionó aquella información que se resaltaba más y la que con mayor frecuencia se resaltaba en cada nota. Podía ser una mención constante en la notica, por su refuerzo visual o porque en sí misma la información llevaba una adjetivación que hacía resaltar la información. La depuración de información en la nota se puede aplicar a datos como los detalles del momento, el lugar, los modos de un actor, antecedentes irrelevantes, cifras precisas, propiedades de las personas y los objetos

\footnotetext{
${ }^{5}$ Un sound bite es "un segmento audiovisual en el que el personaje se muestra y al mismo tiempo se escucha hablar, como audio principal. Estos segmentos pueden provenir de un discurso, entrevistas o conferencias de prensa" (Grabe y Bucy, 2009:286)
}

Facultad de Ciencias Políticas, Sociales y de la Comunicación Universidad de La Laguna Avenida César Manrique, s/n; Campus de Guajara 38071 La Laguna, Tenerife (Islas Canarias - España) 


\section{Principales hallazgos}

En los 30 programas analizados se encontraron 119 notas relacionadas con la reforma, 67 en "El Noticiero" y 52 en "Hechos Noche". De ellas el $90 \%$ fueron informativas y el $10 \%$ fueron de opinión. Los contenidos identificados fueron los siguientes:

- "El Noticiero" abordó más el tema de "Posicionamiento de la reforma" (22.5\%), un poco más desde lo positivo (9\%) que de lo negativo (7.5\%), refiriendo a los personajes de la elite política que se mostraban en favor de la iniciativa. En la "Aprobación de la reforma" también logró un alto porcentaje (22.5\%), con un enfoque mayoritariamente positivo (15\%-). Le siguió "Protestas contra la reforma" (18\%) con un enfoque más negativo (12\%). El "Debate Legislativo" alcanzó un $13 \%$ con un $10 \%$ de enfoque negativo.

- En "Hechos Noche" se identificó más "Aprobación de la reforma" (26.5\%) con una mayoría positiva (19\%). Le siguió "Efectos de la reforma" con un $17 \%$, con un enfoque mayormente positivo (15\%). "Posiciones sobre la reforma $(14 \%)$ se abordó más en forma positiva (8\%).

Cuadro No. 2

Temáticas, enfoques y objetivos del frame en las noticias

\begin{tabular}{|c|c|c|c|c|c|c|c|c|c|c|}
\hline & \multicolumn{5}{|c|}{ EL NOTICIERO } & & \multicolumn{4}{|c|}{ HECHOS NOCHE } \\
\hline & OBJETIVO & POSITIVO & NEUTRO & NEGATIVO & TOTAL & OBJETIVO & POSITIVO & NEUTRO & NEGATIVO & TOTAL \\
\hline IMPLICACIÓN DE LA REFORMA & ISSU & $6 \%$ & $1.5 \%$ & $0 \%$ & $7.5 \%$ & ISSU & $11.5 \%$ & $2 \%$ & $0 \%$ & $13.5 \%$ \\
\hline EFECTOS DE LA REFORMA & ISSU & $10.5 \%$ & $1.5 \%$ & $0 \%$ & $12.0 \%$ & ISSU & $15 \%$ & $2 \%$ & $0 \%$ & $17.0 \%$ \\
\hline POSICIONES SOBRE LA REFORMA & ACTORES & $9 \%$ & $6 \%$ & $7.5 \%$ & $22.5 \%$ & ACTORES & $8 \%$ & $2 \%$ & $4 \%$ & $14.0 \%$ \\
\hline DEBATE LEGISLATIVO & ACTORES & $0 \%$ & $3 \%$ & $10 \%$ & $13 \%$ & EVENTO & $2 \%$ & $6 \%$ & $6 \%$ & $14.0 \%$ \\
\hline PROTESTA CONTRA LA REFORMA & ACTORES & $1.5 \%$ & $4.5 \%$ & $12 \%$ & $18 \%$ & EVENTO & $0 \%$ & $0 \%$ & $9 \%$ & $9.0 \%$ \\
\hline CONSULTA POPULAR & ISSUE & $0 \%$ & $1.5 \%$ & $3 \%$ & $4.5 \%$ & ISSUE & $0 \%$ & $4 \%$ & $2 \%$ & $6.0 \%$ \\
\hline APROBACIÓN DE LA REFORMA & EVENTO & $15 \%$ & $6 \%$ & $1.5 \%$ & $22.5 \%$ & EVENTO & $19 \%$ & $7.5 \%$ & $0 \%$ & $26.5 \%$ \\
\hline & & $42 \%$ & $24 \%$ & $34 \%$ & $100 \%$ & & $56 \%$ & $24 \%$ & $21 \%$ & $100.0 \%$ \\
\hline
\end{tabular}

Fuente: Elaboración propia basado en el seguimiento de los noticiario.

Los personajes que tuvieron mayor espacio en "El Noticiero" fueron el Presidente e integrantes del Gabinete (27\% cada uno), seguidos por los diputados y senadores (23\%), los 
líderes de opinión (11\%), los partidos políticos $(7 \%)$, los empresarios $(2 \%)$ y otros $(3 \%)$. Por otra parte, en "Hechos Noche" quienes aparecieron más tiempo fueron los representantes del gabinete (25\%), seguido por los diputado y senadores (24\%), el Presidente $(21 \%)$, los líderes de opinión (20\%), los partidos políticos (4\%) y otros (6\%).

Figura No. 2

Tiempo dedicado a personajes

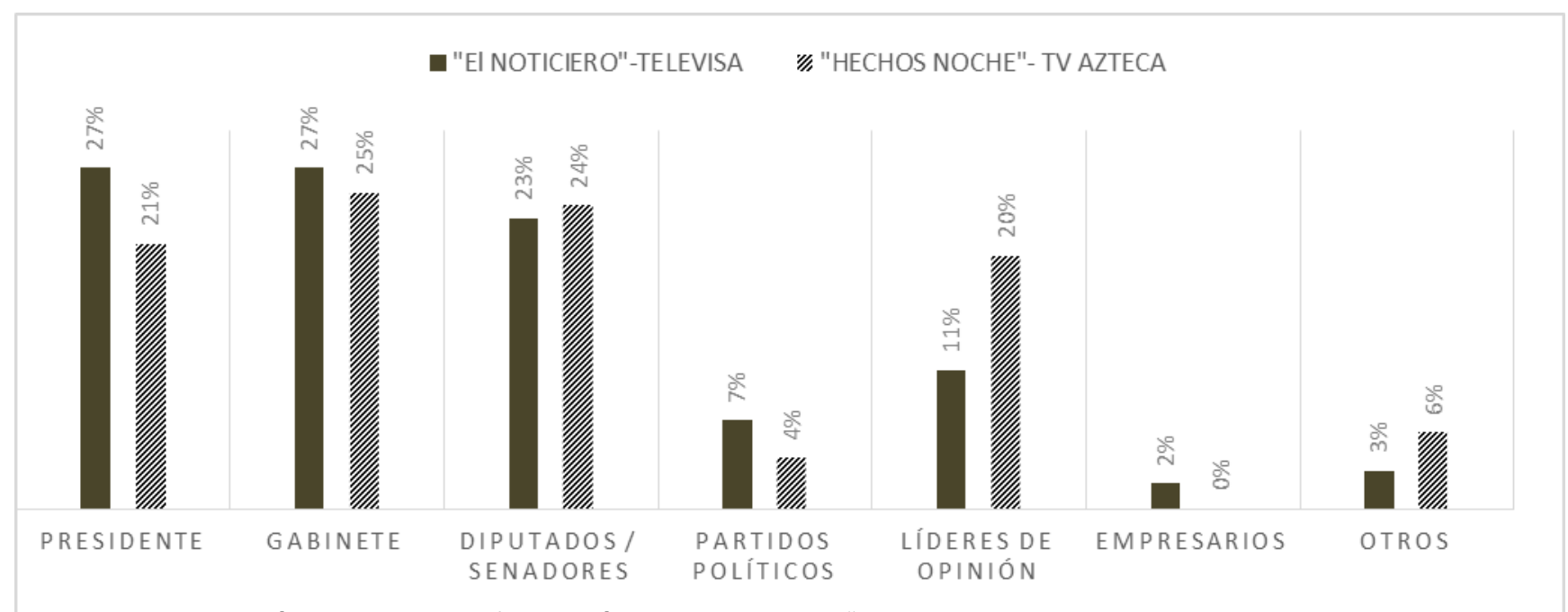

Fuente: Elaboración propia con información del análisis de "El Noticiero" y "Hechos Noche"

\section{5,Análisis por temática}

\section{Temática No. 1.- Implicaciones de la reforma}

\section{El Noticiero}

Planteamiento del problema. - EPN plantea una iniciativa para modernizar el sector energético. A través de cambios constitucionales y retomando el texto del Presidente Lázaro Cárdenas. 
Causa. - Existe un déficit en la producción de hidrocarburos, lo que provoca se eleven los precios de los energéticos, como la luz.

Evaluación moral. - La iniciativa representa el cambio más importante de la última década y uno de los cambios más importantes durante la administración.

Recomendación. - La reforma se plantea para remediar males, superar mitos y tabúes y permitirá un crecimiento potencial de México. Pemex y CFE no se venden ni se privatizan.

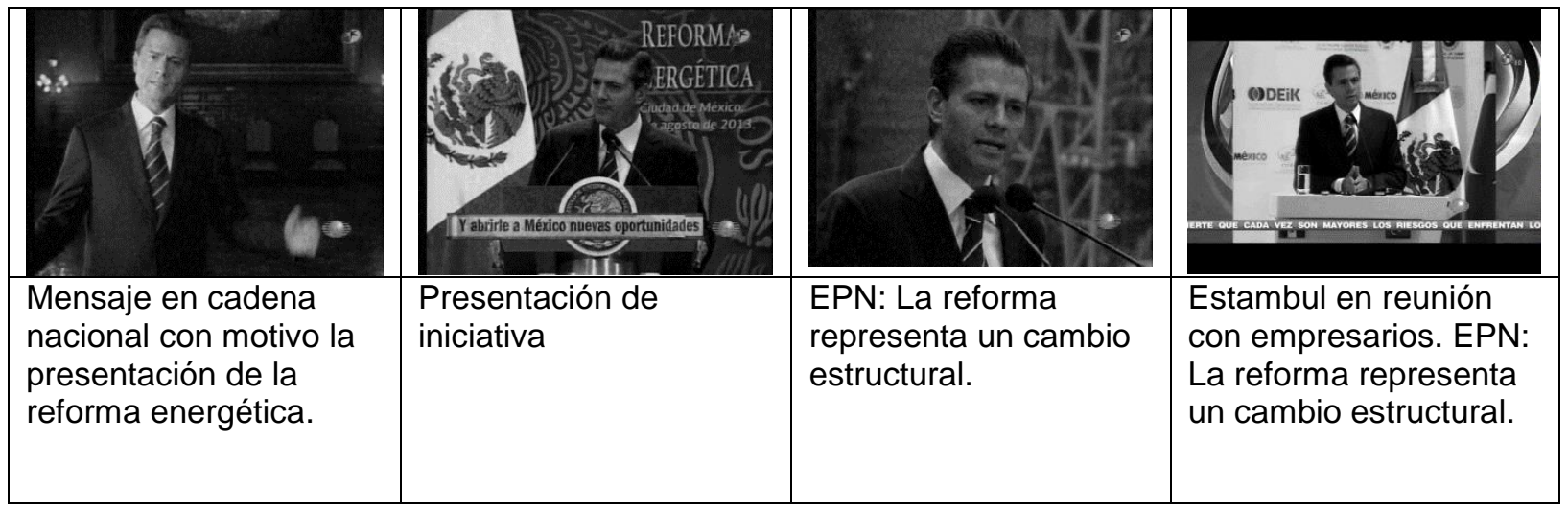

\section{Hechos Noche}

Planteamiento del problema. - El Gobierno Federal plantea la iniciativa de reforma energética para acelerar el crecimiento del país. La iniciativa presentada por EPN propone modificaciones Constitución, retoma el texto del ex Presidente Lázaro Cárdenas.

Causa. - La iniciativa se presenta por el déficit creciente en los recursos energéticos, hay menos capacidad para el abastecimiento de combustible. Esto se debe al poco crecimiento de México.

Evaluación moral. - La reforma traerá beneficios reales para el Gobierno Federal, la iniciativa privada y familias mexicanas. Abrirá las puertas a la economía de México. 
Recomendación. - Es necesario un sector energético acorde al siglo XXI, para el que se requiere el apoyo del sector privado. Es necesario tener más petróleo. En el mundo es común permitir la participación de la iniciativa privada.

\begin{tabular}{|l|l|l|l|}
\hline & & \\
\hline $\begin{array}{l}\text { Presidente EPN ofrece } \\
\text { mensaje en cadena } \\
\text { nacional con motivo de } \\
\text { la presentación de la } \\
\text { iniciativa sobre reforma } \\
\text { energética. }\end{array}$ & $\begin{array}{l}\text { Lo importante de la } \\
\text { reforma será que } \\
\text { mejore la economía y } \\
\text { bajen los precios de las } \\
\text { gasolinas. }\end{array}$ & $\begin{array}{l}\text { Lo que la reforma } \\
\text { busca. }\end{array}$ & $\begin{array}{l}\text { Opinión, EPN presenta } \\
\text { iniciativa. }\end{array}$ \\
\hline
\end{tabular}

\section{Temática No. 2.- Efectos de la reforma}

\section{El Noticiero}

Planteamiento del problema. - Con la reforma bajará el precio del gas, la electricidad y los fertilizantes. Habrá más empleos formarles, bien remunerados. PEMEX Y CFE se fortalecen y serán más eficientes.

Causa. - El crecimiento se dará por el impacto de la reforma propuesta por EPN

Evaluación moral. - Es una reforma audaz y valiente, la más trascendente en las últimas cinco décadas. Con el liderazgo del Presidente de la República veremos los resultados. 
Recomendación. - Es necesaria la discusión y aprobación de la iniciativa de reforma energética. Las mejorías se verán dependiendo del tiempo en que se aprueben, de lo contrario el país puede atrasarse.

\begin{tabular}{|l|l|l|l|}
\hline & & & \\
\hline
\end{tabular}

\section{Hechos Noche}

Planteamiento del problema. - La reforma hará que CFE y PEMEX se fortalezcan, sean más competitivas y estén a la vanguardia. Mejorará la economía de México, reducirá el costo del gas y la luz, se crearán más empleos y beneficiarán a los hogares. Se asegura mayor transparencia en los procesos. La reforma fortalecerá la soberanía nacional. La participación privada no pone en riesgo la rectoría del Estado

Causa. - La aprobación de la reforma es una propuesta del Gobierno Federal y EPN.

Evaluación moral. - Se fortalecerá la soberanía nacional, podrá mejorarse la economía y ampliará la oferta de empleos. La reforma pondrá al país a tono con el mundo.

Recomendación. - La solución pasa necesariamente por la discusión y aprobación de la reforma. Es momento de crecer y quitar trabas que nos han impedido crecer a nuestro máximo potencial. Podrá superarse la escasez y el crecimiento mediocre. 


\begin{tabular}{|l|l|l|l|}
\hline CFE & \\
\hline $\begin{array}{l}76 \text { aniversario de CFE, } \\
\text { La reforma hará de CFE } \\
\text { una empresa más } \\
\text { competitiva }\end{array}$ & $\begin{array}{l}\text { Javier Duarte - Reforma } \\
\text { permitirá a la industria } \\
\text { turística ser más } \\
\text { competitiva. }\end{array}$ & $\begin{array}{l}\text { Análisis de la reforma } \\
\text { energética. Reforma trae } \\
\text { a discusión el futuro del } \\
\text { gas LP. }\end{array}$ & $\begin{array}{l}\text { Opnión sobre los } \\
\text { beneficios de la iniciativa. } \\
\text { Existe una crisis por } \\
\text { escasez del gas natural. }\end{array}$ \\
\hline
\end{tabular}

\section{Temática No. 3.- Posicionamiento sobre la reforma}

\section{El Noticiero}

Planteamiento del problema. - Diferentes reacciones ante la iniciativa, el PRD está dispuesto a debatir, pero no a la privatización. La iniciativa se quedó corta: PAN. No se aprobará una reforma privatizadora: PRD-. Solamente va a ser una reforma modernizadora; PRI.

Causa. - No se deben modificar los artículos constitucionales y debe considerarse una consulta nacional: PRD-. No se propone un modelo de economía desarrollada, es una iniciativa que puede enriquecerse: PAN-.

Evaluación moral. - Hay un sólo objetivo que es transformar y modernizar La reforma presentada por EPN funcionará como en la época de Cárdenas, pues es un modelo probado y tendrá beneficios para los mexicanos: Gabinete federal.

Recomendación. - Alcanzar acuerdos suficientes en el cómo. 


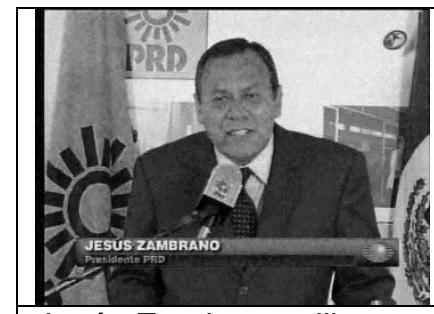

Jesús Zambrano dijo que su partido se opondrá a los cambios constitucionales.

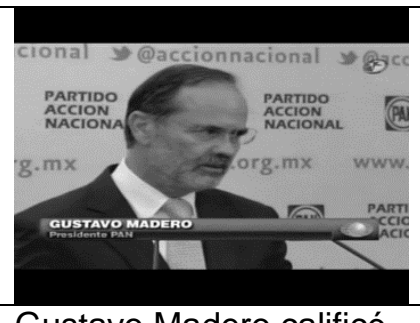

Gustavo Madero calificó de tímida la reforma, no es una propuesta moderna.

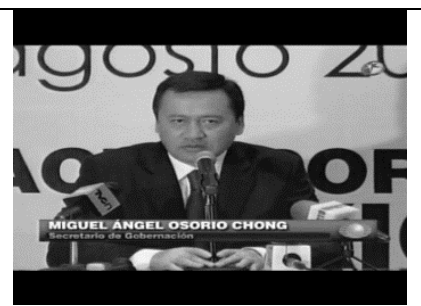

Miguel Ángel Osorio Chong confía en que se apruebe la reforma

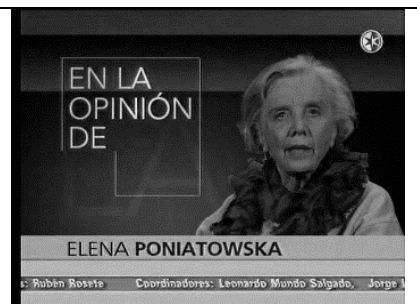

Elena Poniatowska llamó al nacionalismo y cuestionó la entrega del petróleo a empresas privadas.

\section{Hechos Noche}

Planteamiento del problema. - Choque de opiniones sobre la iniciativa de EPN. PRI busca consensos. PAN señala que la iniciativa se quedó corta. La izquierda prepara una contrapropuesta.

Causa. - Los que están a favor consideran que es clave para el desarrollo de la nación. Mientras que los que están en contra señalan que no hay bondades en la reforma y, por el contrario, promueven los monopolios.

Evaluación moral- Mientras unos ven populismo, otros ven excelente oportunidad para sacar adelante a México. EI PRD critica.

Recomendación- La reforma necesita políticos de altura que piensen en las nuevas generaciones, como lo hace el Presidente. Nosotros mismos podemos llegar a bloquear medidas que nos ayuden 


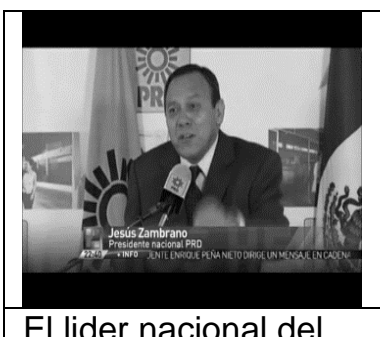

El lider nacional del PRD aprovechó para criticar la propuesta.

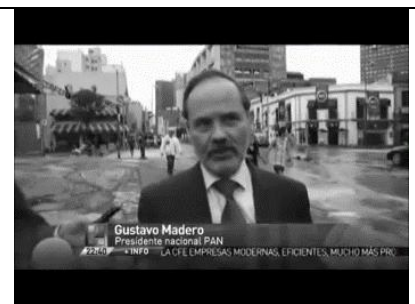

La reforma del gobierno federal no es la que los panistas esperaban.

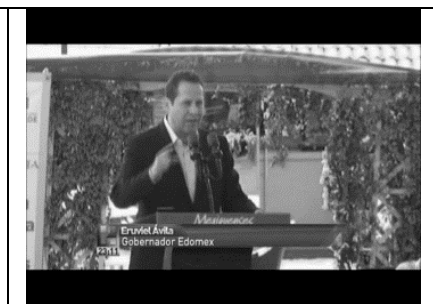

De apoyarse la reforma se impulsaría la competitividad en el Estado de México.

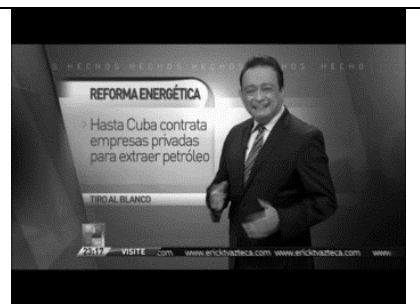

A diferencia de otros países, México no cambia su mentalidad sobre la inversión extranjera.

\section{Temática No. 4.- Aprobación de la reforma energética}

\section{El Noticiero}

Planteamiento del problema. - La reforma se aprueba con los votos del PRI, PAN y PVEM. Los perredistas votaron en contra.

Causa. - Se reconoce al Congreso por la aprobación de la reforma constitucional.

Evaluación moral. - Una nueva generación que sabe la significación del cambio. No tiene temor a lo que hace. Logro trascendental para EPN que pocos tienen en su primer año.

Recomendación. - Los mexicanos saben para que quieren su petróleo, gas y electricidad.

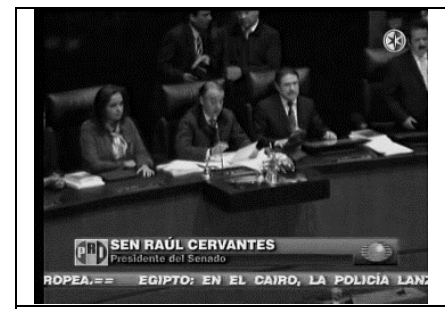

Senado aprobó el dictamen de la reforma energética.

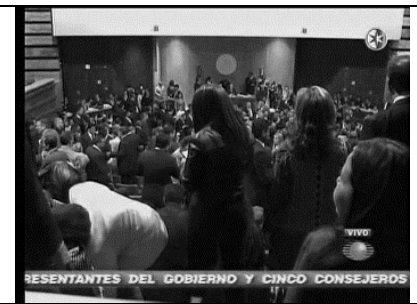

Aprueban la reforma energética en la Camara de Diputados.

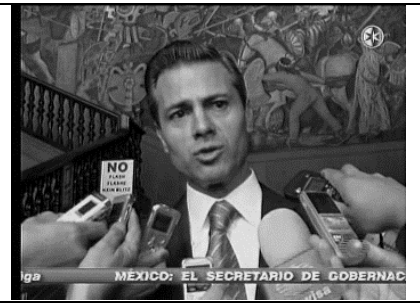

El Presidente hizo un reconocimiento al Congreso por la aprobación de la reforma energética.

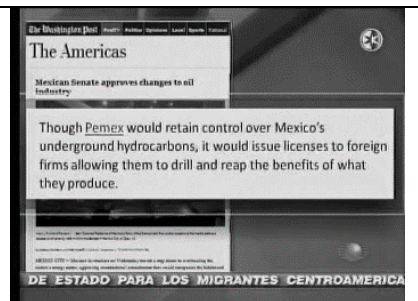

Washington Post calificó como una victoria para el Presidente EPN la aprobación de la reforma enérgetica.

Facultad de Ciencias Políticas, Sociales y de la Comunicación Universidad de La Laguna 


\section{Hechos Noche}

Planteamiento del problema. - La reforma energética propuesta por el Gobierno Federal contempla cambios importantes en la extracción de petróleo y la generación de energía eléctrica. Fue aprobada por amplia mayoría

Causa. - Los legisladores avalan por mayoría la reforma de EPN.

Evaluación moral. - Es un acierto del gobierno mexicano y los legisladores. Ahora que se rompieron paradigmas, México tendrá un verdadero crecimiento y será imparable. El éxito fue construido con argumentos.

Recomendación. - Los cambios están obligados a avanzar.

\begin{tabular}{|l|l|l|l|}
\hline $\begin{array}{l}\text { El Presidente felicitó al } \\
\text { Senado por la } \\
\text { aprobación de la reforma } \\
\text { energética. }\end{array}$ & $\begin{array}{l}\text { Senadores aprueban la } \\
\text { reforma energética. }\end{array}$ & $\begin{array}{l}\text { Después de una larga } \\
\text { sesion la Cámara de } \\
\text { Diputados aprobó la } \\
\text { reforma energetica. }\end{array}$ & $\begin{array}{l}\text { Como una buena señal } \\
\text { califica la clase política } \\
\text { del país la aprocación de } \\
\text { reforma energética. }\end{array}$ \\
\hline
\end{tabular}

\section{Conclusiones y discusión}

Con base en los resultados encontrados, puede asegurarse que ambos noticiarios resaltaron favorablemente la iniciativa de reforma energética presentada por EPN. Aunque con algunas diferencias, los noticiarios alinearon su agenda a la del gobierno en el tema de la reforma energética, reportando la misma información que el gobierno expresaba en relación a la iniciativa, aunque elaboraron sus propios frames. Ambos noticieros presentaron información 
mayormente positiva y reforzaron el mensaje no sólo con fuentes oficiales (como el Presidente y su gabinete). "El Noticiero", dio pie mayormente al debate y las diferentes posiciones con relación a la iniciativa. Sin embargo, el objetivo del frame fue desacreditar al opositor más que argumentar sobre la iniciativa política. Aunque en "Hechos Noche" se encontraron frames que claramente siguieron el discurso de la administración y favorecieron la imagen de EPN, no se enfatizaron los beneficios que era importante resaltar a las diferentes audiencias. Señalar a EPN como un líder fue un hecho que no encajó en la representación social que ya existía. El framing de un Presidente valiente y líder fue popularmente rechazado.

En ambos noticiarios fue recurrente escuchar "PEMEX y CFE no se privatizan", pero fue una frase que no se sustentó suficientemente en datos y referencias confiables. Las asociaciones mentales sobre el tema tuvieron que ver directamente con el "nacionalismo", por lo que la palabra privatizar fue utilizada en forma equivocada en el discurso oficial. De manera similar, la evocación a la figura de Lázaro Cárdenas en el discurso de EPN fue impropio al ser un personaje emblemático adoptado por las izquierdas. Establecer un símil para reforzar "el nacionalismo por el petróleo", más que fortalecer la imagen presidencial generó críticas serias a la administración federal. En efecto, cuando se niega un marco se evoca ese marco. En ese sentido, para discutirse con el adversario no debe utilizarse su propio lenguaje, pues este ya eligió un marco y no será el que uno desea. En consecuencia, fue un error considerar que mantener una imagen negativa de la izquierda serviría para contrarrestar la propaganda que esta hizo en contra de la reforma energética. Con ello se puede suponer que, EPN compartió el mismo lenguaje que el adversario y buscó equivocadamente resignificar el frame "nacionalismo de petrolero". Adicionalmente, no se encontró una estrategia para contrarrestar los tabúes a los que hicieron tanta referencia EPN y los medios de comunicación en los discursos respectivos. Como fue una costumbre, en las noticias el Presidente nunca habló en contra o negativamente de nadie, solamente hizo un llamado a 
una transformación ilusoria. El rechazo a los actores de oposición quedó en manos de su Gabinete, los legisladores y los medios de comunicación.

De esta manera, a partir de los frames encontrados, puede concluirse que, pese al énfasis positivo que los noticieros dieron de la reforma destacándola como una propuesta audaz de un presidente valiente que lograría resolver la economía del país, no se logró posicionar auténticamente la reforma y tampoco se fortaleció la legitimidad del gobierno de EPN. La réplica de los noticiarios puede considerarse como un acto de propaganda más que de información, donde la agenda de los medios se supedito a la del gobierno y respetó siempre la misma línea argumentativa. En esta investigación se ha optado por ver al framing como una estrategia, con la intención de identificar oportunidades para estructurar mejores mensajes. Mediante el framing la noticia establece las condiciones necesarias para definir y entender, en este caso, la reforma energética.

\section{Referencias}

Buendía \& Laredo México: Encuesta telefónica nacional sobre la reforma energética. [Consultado el $\quad 6 \quad$ abril del 2014]. http://vianovo.com/files/Reforma Energ\%C3\%A9tica Cuestionario Resultados.pdf

Cantú J. (2013) Desacato, en Revista de Antropología Social No. 42 Mayo-agosto de 2013. [Consultado el 1 julio de 2013]. http://www.ciesas.edu.mx/

Castells, M. (2012). Comunicación y poder. México; Editorial Siglo XXI.

CESOP. (2013) Encuesta telefónica acerca de PEMEX y la reforma energética. [Consultado el 9 de abril de 2014]. http://www3.diputados.gob.mx/camara/001 diputados/006 centros de estudio/04 ce ntro de estudios sociales y de opinion publica/004 canales secundarios/005 opin ion publica/007 encuestas

Corona G. Las elecciones locales en el Estado de México: La plataforma política de Enrique Peña Nieto a nivel nacional (2009-2011), en Revista El Cotidiano No. 171. México, enero-febrero de 2012 . [Consultado el 01 junio de 2013]. http://www.redalyc.org/articulo.oa?id=32523116004.

Entman, R. (2004). Projections of Power. Framing News, Public Opinion and U.S. Foreign Policy. Illinois: University of Chicago.

Facultad de Ciencias Políticas, Sociales y de la Comunicación Universidad de La Laguna 
Grabe, M. E. y Bucy, E. P. (2009). Imagen Bite Politics. New and the Visual of Elections. New York: Oxford University Press

lyengar S. (1991). Is Anyone Responsible? How Television Frames Political Issues. Chicago: University of Chicago Press

Kahneman, D. y Tversky, A. (2000) Choices, Values, and Frames. EU: Cambridge University Press

Parametría (2013a). Reforma energética en líneas del debate. [Consultado el 7 de abril de 2014]. www.parametria.com.mx/

Parametría (2013b). La expropiación petrolera. [Consultado el 7 abril de 2014]. www.parametria.com.mx/

Presidencia de la República (2013). Iniciativa de reforma energética. [Consultado el 15 enero 2013]. http://www.presidencia.gob.mx/reformaenergetica/\#!leyes-secundarias

Presidencia de la República. (2013) Plan Nacional de Desarrollo. Consultado el 01 de junio de 2013]. http://pnd.gob.mx/

Presidencia de la República. (2012). Mensaje a la Nación del Presidente de los Estados Unidos Mexicanos. [Consultado el 10 de diciembre de 2012]. http://www.presidencia.gob.mx/articulos-prensa/mensaje-a-la-nacion-del-presidentede-los-estados-unidos-mexicanos/

Presidencia de la República. (2012) Firma del Pacto por México. [Consultado el 25 de marzo de 2013]. http://www.presidencia.gob.mx/articulos-prensa/intervenciones-durante-lafirma-del-pacto-por-mexico/

Reuters. Enrique Peña Nieto- Grandes Cambios en un año, en Revista Forbes. México, noviembre 15 de 2012. pp. 106-111. https://www.forbes.com.mx/pena-nieto-a-un-anobaja-popularidad-y-manifestaciones/

Sádaba, T., Rodriguez, J. y Bartolomé, M (2012). Propuesta de sistematización de la teoría del framing para el estudio y praxis de la comunicación política. \{Consultado el 2 de febrero de http://obs.obercom.pt/index.php/obs/article/viewFile/540/564.[Consulta:

2014].

Sádaba, T. (2007). Framing: El encuadre de la noticia. El binomio territorial-medio. Buenos Aires: La Crujia

Van Dijk, T. (1990). La noticia como discurso. Comprensión, estructura y producción de la información. Barcelona, Paidós, 1990

Villamil, G. (2012). Peña Nieto el gran montaje. México: Ed Grijalbo

Wolfsfeld, G. (2011). Making Sense of Media \& Politics: Five Principles in Political Communication. New York: Routledge. 


\section{Forma de citar este artículo en bibliografías}

BAÑUELOS, R (2016): "Encuadres periodísticos y reforma energética: Contribución eficaz a la imagen política de Enrique Peña Nieto", en Revista PANGEA №7, Volumen № 1, páginas 32 a 53. Tenerife: Red Académica Iberoamericana de Comunicación. Recuperado el de de 2 de: http://www.revistapangea.org 